\title{
Gallos de pelea: algunas precisiones desde el diálogo con un gallero
}

\author{
Onésimo Rodríguez
}

\author{
Escuela de Antropología, Universidad de Costa Rica \\ oneboticario@gmail.com
}

Doctor en Ciencias Antropológicas por la Universidad Autónoma Metropolitana de México D.F. Profesor-Investigador de la Escuela de Antropología de la Universidad de Costa Rica. Temas de interés son culturas juveniles, violencia social, cultura barrial y fútbol. Entre sus publicaciones a destacar están: Las peleas de gallos en la prensa escrita costarricense: un Análisis Crítico del Discurso en algunas noticias del diario la Nación S.A. (Rev. Rupturas, 2014), Pandillas, violencia y dinámicas socioculturales en la Costa Rica urbana (Rev. Intersticios Sociales, 2011), Poder y conflicto en una barra de fútbol en Costa Rica: La Ultra Morada (Rev. Digital Académica Esporte y Sociedade, en prensa).

Resumen: El siguiente artículo se desprende de una investigación en curso titulada “'¡Se muere gallo bueno!’ Jóvenes, galleras y gallos de pelea" desarrollada desde la Escuela de Antropología de la Universidad de Costa Rica. Este texto intenta explorar algunas de las realidades vividas por un joven gallero (referidas a las dinámicas relacionadas a la crianza y pelea de gallos) narradas desde su propia oralidad; es decir, la exposición argumentativa de los testimonios se hace desde una perspectiva dialógica que posibilita observar la reflexión y análisis del sujeto de manera extensa.

Palabras clave: gallos de pelea, etnografía dialógica, galleras, galleros.

Abstract: The following article arises from an ongoing research project entitled "'Dying cock good!' Young, cockpits and cockfighting" developed from the School of Anthropology at La Universidad de Costa Rica. This paper attempts to explore some of the realities experienced by a young cocker (referring to the dynamics related to breeding and cockfighting) narrated from his own orality, ie argumentative exposition of the evidence is from a dialogical perspective that enables observe the reflection and analysis of the subject of extensive way.

Keywords: cocks of fight, dialogical ethnography, cockpits, cockers.

Cuadernos de Antropología 2014, 24(1), 37-64

Recibido: 09-06-2014 / Aceptado: 23-06-2014

Revista del Laboratorio de Etnología María Eugenia Bozzoli Vargas Escuela de Antropología, Universidad de Costa Rica http://revistas.ucr.ac.cr/index.php/antropologia ISSN 2215-356X

c) (i) (2) Cuadernos de Antropología está bajo una licencia Creative Commons Attribution-NonCommercial-ShareAlike 3.0 


\section{Introducción}

El presente escrito intenta acercarse a algunas de las vivencias de un joven gallero expuestas desde su propia narrativa. La intención es darle contexto de enunciación a las palabras de este actor y evitar cierta tergiversación con el uso fragmentado y desfigurado de su testimonio. Así parece establecerlo Bourdieu (2010) cuando habla de la confianza y responsabilidad en el manejo de los aportes orales que nos dan los actores (otrora llamados con cierta arrogancia como "informantes”):

Pero ningún contrato está tan cargado de exigencias tácitas como un contrato de confianza. En primer lugar, por lo tanto, debíamos tratar de proteger a quienes habían confiado a nosotros (en especial, cambiando a menudo datos tales como los nombres de lugares o personas que pudieran servir para identificarlos); pero también, y sobre todo, era preciso que intentáramos ponerlos al abrigo de los peligros a los que expondríamos sus palabras si los abandonáramos, sin protección, a las tergiversaciones del sentido" (Bourdieu, 2010, p. 7).

En primera instancia, se intenta argumentar que las reflexiones de los actores (en este caso, las del joven gallero) adquieren sentido por sí solas, que sus análisis son síntomas de situaciones objetivas y subjetivas; es decir, de procesos sociales-sistémicos, pero también de la subjetiva creatividad con que este tipo de personajes deciden afrontar sus cotidianidades.

Esto lleva a la consideración, retomando a Bourdieu (2010), de que ciertos lugares "difíciles" (una gallera clandestina, sectores urbanos pobres) son, antes que nada, "difíciles de describir y de pensar, y que las imágenes simplistas y unilaterales [en especial las vehiculizadas por la prensa] deben ser reemplazadas por una representación compleja y multiple...", referida a la expresión de esas realidades en discursos diferentes y en ocasiones inconciliables.

De esta forma, se intenta presentar el discurso de "Felo" (como en lo sucesivo llamaremos a nuestro joven gallero) con contextos que posibiliten pensar en las diversas especificidades que posee parte de la cotidianidad de un joven que cría y pelea gallos. 
Es importante recordar que los discursos son perspectivas e interpretaciones subjetivas sobre el mundo en que se vive; por tanto, tales apropiaciones suelen develar dinámicas sugerentes desde una construcción contradictoria: la interiorización de las realidades no tienen por qué enmarcarse en procesos socioculturales coherentes (como lo hacían ver las antropologías clásicas), en donde el investigador vaticina una serie de conceptos imbricados con las vidas, proyectos y susceptibilidades de los sujetos. Esto de ninguna manera implica la renuncia a la generación de teoría; antes bien, sugiere la insistencia en desarrollar construcciones dialógicas con los sujetos que den cuenta de otras concepciones y otros mundos encontrados en las palabras e intervenciones de aquellas personas quienes finalmente hacen posible la implementación etnográfica.

El presente artículo, como ya se mencionó más arriba, responde a un proyecto de investigación en curso, el cual, desde la implementación de un enfoque etnográfico ${ }^{1}$, busca dar cuenta de las relaciones entre los y las jóvenes y sus gallos; es decir, las lógicas constitutivas de dicha relación. Se ha publicado un texto (Rodríguez y Alpizar, 2014) y se espera, además del presente aporte, publicar un documento referente a la experiencia y trabajo de campo (etnografía), el cual se realizó desde marzo de 2012 a marzo de 2014.

\section{La construcción del diálogo}

La presentación de la voz de "Felo" (como se verá más adelante) problematiza la forma usual en la que las antropologías clásicas han abordado la participación de aquellos a quienes han intentado "comprender". Intento decir que, salvo casos excepcionales, el papel protagónico en la narrativa de dichas etnografías lo

\footnotetext{
1 Se desarrolló un proceso intenso de observación etnográfica al visitar 5 galleras clandestinas en distintos puntos del Valle Central de Costa Rica. Esas 5 galleras fueron visitadas, cada una, en, al menos, dos ocasiones, siempre con la compañía de los chicos de La Gotera (criadero de gallos ubicado en Heredia), espacio que desapareció por la muerte de su joven dueño. Estas visitas y convivio etnográfico con los jóvenes galleros fueron registrados en la libreta de campo; además, se hizo una entrevista con "Felo", la cual se presenta en este documento. La forma de contactar a estos jóvenes fue relativamente sencilla: el autor de este texto procede de la misma localidad que los muchachos "sujetos de investigación" quienes decidieron colaborar con la investigación de manera inmediata, una vez que se les propuso el proyecto. A ellos, gracias. Fundamentalmente a "Felo", joven conocedor de gallos finos.
} 
tenía el investigador ${ }^{2}$, el cual emergía, en muchas ocasiones, como representante de poderes coloniales ${ }^{3}$; en tanto, la voz de los otros culturales, los "nativos" o los "informantes" quedaba relegada.

Este artículo busca apartarse de esas miradas tradicionalistas que invisibilizaban la participación de los “Otros culturales” en la elaboración del texto etnográfico, Clifford argumenta al respecto:

Se hace necesario concebir la etnografía no como una experiencia [malinowskiana] y la interpretación [geertzsiana] de "otra" realidad circunscrita, sino más bien como una negociación constructiva que involucra por lo menos a do, y habitualmente a más sujetos conscientes y políticamente significantes. Los paradigmas de la experiencia y de la interpretación están dejando el paso a los paradigmas discursivos del diálogo y la polifonía (2001, p. 61).

2 Tanto en Argonauts of the western pacific de Malinowski (1932) como en La Interpretación de las culturas de Geertz (1989) y Tristes trópicos de Levi-Strauss (1988), así como en Los núer de Pritchard (1991), los protagonistas han sido, al final de cuentas, estas legendarias y míticas figuras de la antropología y la etnología.

James Clifford da cuenta de estas posturas clásicas en la antropología; así, por ejemplo, hace referencia al "etnógrafo de los núer": "Mientras plantea exigencias muy limitadas y no hace ningún secreto de las restricciones que pesaron sobre su investigación, Evans Pritchard se las ingenia para presentar su estudio como una demostración de la efectividad de la teoría. El enfoca su atención sobre la política y la "estructura social" de los nuer, analizada como un conjunto abstracto de relaciones entre segmentos territoriales, linajes, grupos de edad y otras agrupaciones más fluidas (...) distingue tajantemente entre su método y lo que él llama documentación (malinowskiana) fortuita (...) [argumentando] que los hechos solo pueden ser seleccionados y ordenados a la luz de la teoría" (2001, p. 51), lo cual sugiere una preeminencia de la teoría por sobre los hechos (realidades de los actores). Clifford sigue refiriéndose a esa forma tradicional de hacer antropología. Parte de su crítica, ahora, se concentra en el "antropólogo interpretativo": "La abrupta desaparición de Geertz en su rapport, la cuasiinvisibilidad de la observación participante, son paradigmáticas. Aquí Geertz se sirve de una convención establecida para escenificar el logro de la autoridad etnográfica. Como consecuencia, rara vez nos damos cuenta del hecho de que una parte esencial de la construcción de la riña de gallos como texto es dialógica: el autor hablando cara a cara con los balineses particulares, más que leyendo la cultura 'por encima de los hombros"” (2001, p. 61).

Por último, la reflexión de Clifford (2001) culmina con una llamada de atención acerca del aporte del, por muchos considerado, "padre del trabajo de campo etnográfico": "De esta manera, por ejemplo, el etnógrafo de los isleños trobriandeses no fragua abiertamente una versión de la realidad en colaboración con sus informantes, sino que más bien interpreta "el punto de vista trobriandés".

En síntesis, la idea de James Clifford con esta deconstrucción de las ideas y aportes de ciertos antropólogos clásicos es abonar a la consolidación de una nueva autoridad etnográfica (más allá de la experiencial e interpretativa) de tipo dialógica concebida desde el aporte de Bajtín, esto es, en diálogo constante con los sujetos. Ahora bien, esto de ninguna manera desmerita la trascendental contribución de estos célebres antropólogos y etnólogos, contribución que es reconocida por Clifford, solamente llama la atención sobre la ausencia de voz de aquellos que figuran en dichos textos como "informantes".

$3 \mathrm{Al}$ respecto, Mignolo (2010) llama la atención sobre la importancia de, en un contexto de colonialidad, intentar un ejercicio de emancipación del poder, a través de una descolonización de la mente: "si el conocimiento es un instrumento imperial de colonización, una de las tareas urgentes que tenemos por delante es descolonizar el conocimiento". Para esto, es necesario implementar estrategias de aprendizaje diversas, pero sobre todo que respondan al poder instituido como parece establecerlo Freire (2012) en su aprendizaje humanista, responsable y liberador de las voces oprimidas.

\section{http://revistas.ucr.ac.cr/index.php/antropologia}


Así, el autor retoma el aporte de Bajtín para la construcción de esta nueva forma de autoridad etnográfica:

Cada uso de yo presupone un tú, y cada instancia de discurso está inmediatamente ligada a una situación compartida específica: no hay significado discursivo, entonces, sin interlocución y contexto la relevancia de este énfasis para la etnografía es evidente. El trabajo de campo se compone significativamente de sucesos lingüísticos; pero el lenguaje, según Bajtín, está en el límite entre uno mismo y el otro. La mitad de la palabra es del otro. El crítico ruso urge a repensar el lenguaje en términos de situaciones discursivas específicas: "No existen -escribe- palabras y formas 'neutras', palabras y formas que puedan no pertenecer a 'ninguno'; el lenguaje ha sido poseído por completo por intenciones y acentos". Las palabras de la escritura etnográfica, por lo tanto, no se pueden construir como si fueran monológicas, como afirmaciones autoritarias sobre, o como interpretaciones de una realidad abstracta y textualizada. El lenguaje de la etnografía está afectado por subjetividades y por resonancias contextuales específicas, puesto que todo lenguaje, en la concepción de Bajtín, es "una concreta visión heteroglósica del mundo" (Clifford, 2001, p. 61-62).

Esta dimensión polífónica de la forma de hacer etnografía supone un compromiso con los actores de la trama sociohistórica, el cual se funda en la consideración de que sus discursos son entramados lingüísticos densos y complejos que ameritan una exposición suficiente que dé cuenta de una heteroglosia etnográfica ${ }^{4}$. De esta forma, según Clifford (2001): "si se les acuerda un espacio textual autónomo y se las transcribe en longitud suficiente, las afirmaciones indígenas [en este caso, las de "Felo"] tendrán sentido en términos diferentes a los del etnógrafo que las manipula"5.

\footnotetext{
4Así lo entiende Renato Rosaldo (1989) en su ya clásico Cultura y verdad. Nueva propuesta de análisis cultural. Donde expone una incisiva crítica a la antropología clásica, partiendo de su estudio con los Ilongotes en las tierras altas de Filipinas, con quienes establece una relación dialógica en la cual, lejos de forzar sus a priori teórico-metodológicos, decide escuchar diferentes historias de los "nativos" relacionadas con la práctica de la caza de cabezas. Rosaldo, después de varios años de meditación sobre estas historias, comprende que el texto etnográfico es una versión de la realidad dialógicamente construido.

$5 \mathrm{Al}$ respecto de la coautoría etnográfica, Clifford la considera aún, una utopía por dos razones: "primero, los escasos experimentos recientes con obras de autores múltiples requieren, como fuerza instigadora, el interés investigador de un etnógrafo quien al fin y al cabo asume una posición editorial ejecutiva. La instancia autoritaria de 'dar voz' al otro no es trascendida por completo. Segundo, la idea misma de la autoría colectiva desafía una profunda identificación occidental del orden de cualquier texto con la intención de un autor singular"; sin embargo, "como quiera que sea, hay signos de movimiento en este dominio. Los antropólogos tendrán que compartir sus textos cada vez más, e incluso tendrán que compartir las portadas, con aquellos colaboradores indígenas para quienes el término informantes ya no es más adecuado, si es que alguna vez lo fue” (Clifford, 2001, p. 71).
} 


\section{Algunos datos biográficos sobre "Felo"}

"Felo" es un joven de 27 años, reside hacia el norte de la ciudad de Heredia, a escasos 30 minutos de este centro urbano, en un pueblo que pareciera metaforizar una transición entre interacciones y procesos rurales y urbanos. Completó el tercer ciclo de educación básica y actualmente labora en construcción como maestro de obras (se tituló del Instituto Nacional de Aprendizaje -INA-). Vive con su familia: padre, madre y hermanos y, como él mismo dice, aún no se ha casado, ni tiene hijos.

Este joven, en sus tiempos libres, se dedica a la crianza de gallos ${ }^{6}$; según él, tiene más de 10 años criando y peleando gallos. Suele reunirse, en algunos sitios públicos del pueblo (plaza, parques, etcétera) con otros jóvenes de la zona. Algunos de ellos también gustan de las actividades relacionadas con los gallos, pero, según el proceso de observación llevado a cabo para la investigación de la cual se desprende este artículo, "Felo" es el único que mantiene una relación constante con este tipo de dinámicas: durante todo el año tiene gallos a los cuales cuida (alimenta, desparasita, vigila, supervisa) y entrena para una posible pelea. Lo cual

6Algunos autores (Fernández, 1984 y Urbina, 2000) mencionan la existencia de dinámicas referidas a la crianza y peleas de gallos, por lo menos, desde finales del siglo XIX; incluso, para aquel tiempo, como sucede hoy, se daba la participación de figuras políticas destacadas en estos eventos, por ejemplo, el expresidente de la República Ricardo Jiménez Oreamuno, quien, a principios del siglo pasado, promueve un veto a esta actividad por considerarla "incivilizada" a pesar de su reconocida afición por los gallos de pelea (Fernández, 1984). Así, desde ese entonces, las peleas de gallos son prohibidas en nuestro país.

Además, es importante acotar que, según el proceso de observación etnográfica desarrollado en el marco de la investigación “¡Se muere gallo bueno! Jóvenes, galleras y gallos de pelea”, estas dinámicas en la actualidad se llevan a cabo en redondeles improvisados y clandestinos. Se han visitado un total de 5 galleras ubicadas en el Valle Central de Costa Rica (Alajuela, Heredia, Cartago y San José); sin embargo, también "se juegan gallos" en el resto de provincias del país, esto según los testimonios de galleros y la información de prensa escrita.

Estos redondeles, construidos con restos de madera y latas de zinc, suelen estar ubicados en fincas. Pueden albergar entre 100 y 300 personas; generalmente asisten hombres adultos, pero también se pueden observar hombres jóvenes, niños y, en menor número, mujeres adultas, jóvenes y niñas. La tarifa por el ingreso a estos eventos oscila entre los 2.000 y los 5.000 colones; las galleras también cuentan con un parqueo improvisado en donde los galleros dejan sus carros. Dentro de las galleras hay un espacio destinado a la venta de comida (típica "cocina" costarricense), en donde, generalmente, trabajan únicamente mujeres, hay también un comedor, por lo menos una pileta para limpiar a los gallos heridos, un sector de sanitarios y pequeños espacios debajo del redondel en la parte anterior para preparar a las aves que van a pelear (acá se alista al gallo: se le cortan las uñas y se le montan las espuelas de carey). Por último, está la "arena" o el lugar preciso donde los gallos pelean, los cuales son vitoreados por las y los asistentes ubicados en las tablas del redondel. Uno o dos réferis se encargan de impartir justicia dentro del recinto; las peleas están pautadas para durar no más de 10 minutos. Muchas de las peleas, que fueron posibles observar, duran los 10 minutos. Algunas de ellas se definen en menos de esos 10 minutos reglamentarios, la minoría tarda entre 1 y 5 minutos y, casi de manera excepcional, un gallo tiene la capacidad de ganarle al otro en menos de 1 minuto. Otra de las dinámicas que se pudo observar fue la de las apuestas. Los galleros y muchos (as) de los (as) asistentes apuestan en prácticamente todas las peleas, pero, fundamentalmente, en la que participa el gallo propio o el gallo de un amigo cercano. Desde esta perspectiva, gran parte de la teatralización de las peleas de gallos obedece a un asunto económico; es decir, la apuesta es importantísima (diríamos que trascendental) en la dinámica de las galleras.

En una próxima entrega, con el material etnográfico sistematizado y analizado, se discutirá acerca de si las peleas son o no una práctica cultural; además, se abordará en profundidad esta lógica de la "apuesta”, así como otras dinámicas relevantes observadas durante el proceso de trabajo de campo.

\section{http://revistas.ucr.ac.cr/index.php/antropologia}


no sucede con los otros chicos, quienes no tienen gallos todo el tiempo, sino de forma esporádica.

En "Felo" hay una especie de fascinación dirigida hacia estos animales: suele hablarles con dulzura: “qué, papi, ¿cómo está?”, le preguntaba, al momento de la entrevista, al que según él era el mejor gallo que tenía, mientras lo acurrucaba en sus brazos, "qué lindo que se ve hoy, mae", con una mezcla de ternura paternal y soporte emocional, porque como él dice: "Los gallos entienden, ellos saben". Esta actitud sentimental hacia las aves no es única de "Felo", durante las visitas a las galleras (redondeles donde se juegan los gallos), fue posible observar conductas similares de otros galleros, algunos incluso besaban y se metían la cabeza del gallo ensangrentado en la boca para aliviarlos de sus heridas después de la pelea (La entrevista formal con "Felo", fue realizada el 12 de noviembre de 2013 en San Roque de Barva de Heredia.

\section{“...Mae, le doy 5 mil ya y me deja ese pollo a mí..."}

Este apartado tiene la intención de visualizar el comienzo de "Felo" en la actividad gallera. Las razones esgrimidas por este actor, como se verá, corresponden a situaciones espontáneas más relacionadas con dimensiones emocionales que con una racionalidad específica. Se intenta anunciar que los sujetos eligen, a veces, de forma rutinaria sus afinidades, las cuales irán densificando en la apropiación paultina de las dinámicas del entramado cultural en cuestión.

O: Ehm... ¿Cómo empezó con esta vara de los gallos, mae?

F: Fue algo que ni siquiera yo me explico. Yo llegaba todo... Siempre me gustaron, pero fue algo así, ni mi familia, ni mi tata, ni mi mama, mi mama no lo soporta, mi madre para nada, no los quiere para nada... Es más, yo no puedo tener gallos en mi casa, solo pollitos. Llevo pollitos chiquititos, ya cuando empiezan a cantar... "lléveselos"... porque sabe que los voy a pelear.

Yo salía a trabajar, pasaba por una calle ahí por mi choza y había un paisilla7; cuando yo pasaba en la pura mañana, él sacaba los gallos a la cerca, así en la pura cerca de la casa y los ponía a asolear, y yo "qué lindo es esta vara" "qué lindo ah"... Ya así seguí trabajando y la vara, entonces yo pasaba con mi tata y me decía mi tata "no, no, no, no, eso no sirve para nada", ta bien...

Ya entonces empecé y me compré el carro mío, entonces ya yo iba a trabajar solo. Entonces un día, igual pasé en la tarde y me dio la curiosidad y pasé, le toqué la puerta al señor y yo “¿qué tal?”, el mae se llamaba William, y me dice “¿qué tal?” y

\footnotetext{
7 Paisa: designación, en ocasiones despectiva, referida a la persona de origen nicaragüense.
} 
no sé qué, hicimos amistad y yo llegué con los gallos y yo "qué gallos más lindos" y me dice "¿usted tiene gallos?” y yo "no, no, no, solo que siempre me han llamado la atención”, entonces él me empezó a enseñar y ahí empecé a pasar todos los días, después del trabajo a las 5 de la tarde, de 5 a 7 me quedaba con él, viendo cómo entrenaba los gallos, igual él trabajaba, entonces empezaba a trabajarlos en la noche...

Y ahí empecé y empecé y un día tenía un amigo, que él sí tenía gallos desde chiquitillo, pero él se había quitado, tuvo gallos cuando estuvo pequeño, pero se había quitado y después era amigo mío toda la vida, entonces después como él vio que yo estaba con ese mae que tenía gallos, entonces él se empezó a meter y un día estaba yo con el paisa ahí sentados y llegó el amigo mío con dos gallos, un gallo negro y un gallo blanco, pinto: blanco negro... El gallo negro él lo había comprado como en 20 mil pesos y el otro se lo habían dado por 5 mil, que se llevara los dos. Apenas llegó y le dijo "mae, vea paisa tengo este gallo" y el paisa se enamoró del gallo negro, un gallo negro lindísimo, y dice "y compré esta cochinada en 5 mil", entonces le digo yo “¿de verdá, Camilo?”, “sí, mae Felo, lo compré en 5 mil” y le digo "mae le doy 5 mil ya y me deja ese pollo a mí", “¿le gusta? Yo lo iba a matar" y le digo yo "no, no, démelo, yo le doy 5 mil" y le doy los 5 mil pesos y me lo dejé, y le dije "paisa, ¿me lo cuida?" y me dice "sí, sí, sí, yo se lo cuido, tranquilo. Nada más tráigame la comida”. Entonces yo empecé y empecé, le compré la comida, empezamos, ya lo peluquiamos, lo alistamos pa' peliar...

Muy bien, jugamos el gallo negro, la primera pelea matado, muerto. Seguía el mío, veá. Llegamos el pai y me dice "mae, Felo, ¿cuánta plata tiene?” y yo "no, yo tengo 20 mil", "entonces yo le pongo 10 y vamos con 30 rojos en la primera pelea”. Yo no sé si fue la vara mía que tanto me gustó el gallo y tanto amor le puse que el gallo mío llegó y pum-pum, en menos de un minuto ya tenía al otro gallo despedazado, despedazado, mae. Iba con 30 mil, pero el... Iba con un señor que era muy conocido tal vez en ese tiempo, yo no conocía a nadie ni sabía nada de qué era, ¡nada! Qué era una pelea, qué era nada, era la primera vez que yo iba...

Entonces toda la gallera le fue al señor [apostaron al gallo del señor], pero a mí se me arrimó un mae de esos que le llaman "maceadores", no llevan ni gallos, a ellos

8 Cochinada: algo sucio, repulsivo, que se tiende a evitar. En el contexto de la narrativa: un gallo que no sirve.

9Apostadores que no llevan gallos. Macear, en el lenguaje popular costarricense, tiene una congnotación sexual y sugiere, tocar o acariciar con algo de exceso. En estos términos, el maceador "acaricia" o "se aprovecha" del gallo de otro. 
lo que les gusta es jugar plata, se me arrimó y me dice "qué gallo más lindo, chiquillo, ¿es suyo?” y le digo "sí es mío", “qué lindo, ¿le gusta?” y yo "no sé, yo lo compré en 5 mil", “¿de verdad" me dice, "sí”... Y el mae no sé, tal vez se le metió la misma vara mía, y el mae le empezó a apostar, y como era maceador, entonces apostaba 10 mil, 10 mil, y agarró como 100 mil pesos, mae. Yo le decía “¡usté está loco, mae! ¡Usté está loco!”, “déjelo, déjelo, de por sí, gano o pierdo, esta vara es así”. Son maes que di, estoy hablando que andan un fajo de un millón de pesos tal vez... Agarró el gallo mío y ipum-pum-pum-pum! Un minuto, no había gallo, mae, despedazado. Ese mae me agarró, mae, en medio del redondel y me tiraba para arriba, me decía “¡ve, hijueputa, ve, ve!”...

Ya en esa pelea nos lo trajimos, lo curamos, 15 días después lo volvimos a llevar a la misma gallera. Apenas llegó el gallo, se me arrima el mae y me dice ¿qué, chiquillo, trajo el mismo gallo?”, "sí, aquí lo traigo", “jok!”... Ya sale así, me dice "mae, sale con 100 mil", "pero nosotros apenas traemos 50 pa’ jugarlo" le digo yo, “ ¿y si el mae no quiere echarlo con 50?”, “no, no importa”, y se arrimó donde el mae “¿cuál mae es?", digo yo "aquel mae es"; "mae [dirigiéndose al opoente del gallo de "Felo"], el mae no tiene plata pa' jugarlo, pero yo lo voy a apadrinar, ¿con cuánto juega el gallo suyo?", “di, con 100 mil”, “di no, juguémoslo con 200”, "ta bien” le dice el señor...

¡Pum! 200, igual. ¡Pum, pum, pum! De ahí, di, ganó el gallo mío, ahí siguió haciendo peleas y peleas, mae, ese gallo yo le hice como 13 o 14 peleas si no me equivoco, pero un gallo de primera. Si yo tuviera el día por hoy ese gallo, mae, yo creo que sería el mejor gallo que he tenido en mi vida...

"Felo", con un poco de épica, nos resume sus inicios en las peleas y crianza de gallos. La emocionalidad del discurso se torna densificada toda vez que es posible reconocer el paulatino proceso de incursión del actor en la cultura gallera. En esta densificación cultural aparece un elemento que se irá repitiendo en el discurso de este actor: la dimensión económica (apuestas, costos, dinero, valor del gallo, etc.), trascendental en la lógica de las peleas y crianza de estos animales.

\section{"Nadie vende lo bueno... uno va aprendiendo"}

La aprehensión del conocimiento es fundamental. Si los inicios implican cierta espontaneidad, esta parte de comprender e internalizar la cultura gallera es compleja, suponiendo, en los términos de "Felo", una significancia didáctica. La cultura se aprende, se puede incluso renegociar, pero no es algo, a pesar de ciertas referencias populares al respecto, que se "lleve en la sangre". 
F: Después de ahí, mae, yo me empecé a enfiebrar ${ }^{10}$, la fiebre, yo pensé que todos los gallos eran iguales, mae, que con todos iba a ganar igual, mae, que todos iban a ser buenísimos. Entonces empecé a comprar gallos aquí, a comprar gallos allá y comprar gallos acá, y ya empecé a venir a las galleras; entonces ya empecé a aprender cosas, ya me empezaron a matar gallos, ya empecé a perder, yo decía "no, esta vara no, mae", yo me acuerdo que todos los señores me decían "es que usted no hace nada con comprar, comprar y comprar, porque nadie vende lo bueno", todos los viejillos me decían eso, "nadie vende lo bueno". Siempre lo bueno aquí se lo dejan, a usted le van a vender la cochinada, más si usted no sabe nada, mejor saque los suyos, "empiece a sacar los suyos". Me decía un señor, "le voy a dar una gallinita, ¿usted tiene un gallo bueno?”, "yo tengo un gallo bueno ahí", era ese gallo... "Sáquele pollos", y le empecé a sacar pollos y no me sirvieron para nada, mae, para nada. Y el gallo mío era el primero, para nada me sirvieron, entonces yo: "qué raro, mae", si el gallo mío es bueno y si el señor me dijo que la gallina era buena, entonces empecé a seguir y a seguir, hablando con la gente, entonces la gente dice que, di, la sangre lo liga, usted puede tener el gallo más bueno y la gallina más buena, que si usted los cruza y genéticamente ellos no son compatibles, di, sale malo, mae. Entonces, ahí empecé a aprender cosas, empecé a aprender, mae, hasta que llegué al punto en que digo yo di, de verdad que, que en esta vara no se gana nada, ni siquiera...

O: ¿Pero cómo sabe uno que son compatibles genéticamente?

F: No se sabe hasta que los pruebe o tiene que esperarse un año, un año...

O: A que el gallo tenga un año...

F: A que el gallo tenga un año para poderlo usted pelear. Igual usted puede tener, digamos, una gallina que usted diga "mae, esta gallina viene de tal hijo, de tal padre" digamos, y yo se la voy a echar a un gallo bueno, pero usted no se va a dar cuenta si los pollos van a salir buenos hasta que tengan un año y usted los pelee.

O: El pollo se sabe que es bueno hasta la primera pelea.

F: Hasta la primera pelea.

10 Involucrarse más en la actividad. En otros contextos, a este proceso se le suele llamar "calentura", haciendo referencia a una enfermedad (fiebre) que se decide portar en el cuerpo. 
O: Pero entrenándolos como hacía el hombre ahora, ¿no? [me refería a un señor, amigo de Felo, que nos acompañaba ese día, el cual estaba entrenando uno de los gallos].

F: Sí, porque, digamos, yo en este momento, ya con la experiencia que yo tengo, yo le puedo decir a usted "ese gallo no sirve para nada", pero es por la forma en que ellos juegan. Digamos, el estilo, el ánimo, el vigor que tenga el gallo, las patadas que pegue, la fuerza donde él pegue, cómo él juegue. Yo ahí me puedo dar cuenta, más o menos, no exactamente, que si el gallo es bueno o es malo. En este momento, yo puedo agarrar e irme para un criadero de gallos y que me digan, mae, yo voy y compro un gallo; lo primero que hago es decirle a usted, digamos, usted es el dueño del criadero, "me gusta ese gallo, ¿por qué no lo topamos para verlo?" entonces usted me lo topa con otro gallo, entonces yo solo viéndolo, entonces digo yo "sí, está bien, sí me gustó" o "no, no me gustó".

Eso es más que todo instinto, como le digo, ya uno va aprendiendo, como el gallo pelea, la fuerza que él tira, el ánimo, más que todo el ánimo y el vigor, como él entra a peliar, si a él le gusta que le den, si a él no le gusta, si él se quita los tiros, si él es tonto nada más va para adelante, si el gallo empieza a peliar agachado, si el gallo empieza a pararse mucho. Los viejillos dicen que el gallo parado no sirve, no sirve porque es refinado ${ }^{11}$, entonces el gallo cuando se para lo que no le gusta es que le den; aquí dicen que el gallo fino se agacha, entre más duro le den, él se mete a peliar para adentro, para adentro, entonces agacha la cabeza y va para adentro, pal' gallo, pal' gallo, pal' gallo, a la pechuga, al ala, va para adentro. Aquí a la gente le gusta que el gallo se meta a peliar abajo, tire más al cuerpo, las espuelas más al cuerpo.

En Puerto Rico, en República Dominicana, son gallos más juperos ${ }^{12}$, tal vez más delgados, entonces tiene más fácil que maten al gallo, más delgado del pescuezo para arriba más pequeño, pero es que ahí juegan con espuela plástica y medida; ahí, digamos, ahí usted en Puerto Rico usted lleva un gallo que pesa tres ocho ${ }^{13}$ y usted lo entrega, como es legal, hay reglas y hay un reglamento, entonces usted llega y entrega el gallo a la gallera...

11 "Felo" me explicaba que hay una diferencia entre el gallo fino y el refinado. El primero es el gallo de poco cruce (genéticamente hablando), un animal "puro"; el segundo, más bien está muy cruzado y no sirve, pues, según los galleros, su sangre está muy mezclada.

12 Cabeza grande, cabezones.

13 Libras

Cuadernos de Antropología 2014, 24(1), 37-64 
Sí, usted llega y pone “bueno, el gallo mío va a jugar con $\$ 500 ”$, entonces usted llega y pone los $\$ 500$ y entrega el gallo y se va. Ellos agarran y ponen el gallo encerrado, todo cerrado, le ponen el color de una vez y ellos mismos programan la pelea con otro tres ocho [otro gallo del mismo peso] y cuando la pelea está lista para jugar, tal tiene la 17, ok, lo llaman a usted por un micrófono, por los parlantes, "bueno usted tiene la pelea 17, venga para acá" y le dan las espuelas. Son las espuelas que usa cada gallo... Entonces los gallos pelean con la misma espuela, el mismo tamaño. Aquí no, aquí yo llego y le pongo la espuela que a mí me da la gana, si quiero le pongo una espuela de 1 centímetro o, digamos, de 1 pulgada, a digamos una de 2 pulgadas...

O: Sí, usted mide...

F: Yo mido cómo mi gallo pelea. Como no es legal y no hay reglas de nada, entonces tiene que ver mucho, veá... Por lo general, un gallo agachado tiene ventaja, que siempre va al pulmón o al corazón, un órgano más fuerte...

O: ¿Dónde los cría, Felo?

F: ¿Yo? En este momento tengo poco espacio porque, diay, tuve un problema ahí; entonces, antes sí teníamos un criadero muy grande, ahí, usted lo conoció, La XXXX, sí... Ahí teníamos un criadero muy grande, teníamos casi 50 rejones, sí, peliamos, sí, todo el año pasamos peliando, los viernes, sábado y domingo pasábamos en la gallera, metidos, él y yo, entonces mi amigo se murió, él tenía un campo muy grande, y yo, como le dije ahora, en mi casa no puedo tener, mi mama no me deja, no me deja...

La crianza y peleas de gallos, como lo ha narrado "Felo", son actividades complejas que requieren de la captación de cierta lógica sistémica que no se reduce a lo efímero o circunstancial. El aprendizaje gallero, como en cualquier proceso sociocultural, tiene sus matices que casi siempre denotan profundidad (en los términos de Geertz, 1989).

\section{"Ya, ya... mi gallo está listo"}

En esta sección, se presentará la forma en la que se cría y se entrena un gallo con vistas a una futura pelea. Según "Felo", este es uno de los procesos más importantes de la crianza; la dedicación al gallo y los pequeños detalles (comida, vitaminas, cuido, etc.) son muy importantes, pues esto definirá la calidad del animal a la hora de la pelea. Es interesante que "Felo", en este sentido de preparación y sistematicidad, hace la comparación del gallo con un deportista. 
O: Ajá. Sí... ¿Y cómo hacen, mae, qué hay que hacer para criar un gallo? Desde que está pollito...

F: Primero que nada, diay... O, perdón... Hay que... Escoger su línea y lo que a usted le gusta de un gallo. Eso es lo primero que usted tiene que hacer, escoger. Si usted tiene un gallo que... Como la pluma, la pluma tiene mucho que ver, porque, digamos, por ejemplo, a mí me gusta la pluma chile ${ }^{14}$, yo siempre he dicho que la pluma chile es la primera, un gallo más fino, más sangre, más todo tiene. Entonces, digamos, yo por ejemplo a mí me gustaría tener todos mis gallos que sean chiles, todos, y que yo llegue a una gallera y desde que usted entre y usted diga "no, sí, este gallo es de Felo porque es chile", si yo llego con un gallo de otro color no es mío. De segundo, escoger de cómo a usted le gusta que el gallo pelee, si el gallo a usted le gusta que el gallo pelee agachado, hay gente que le gusta que pelee más parado, que tenga más energía, que pelee fuerte, todo eso tiene que irlo escogiendo usted y ahí... Es un proceso, todo es un proceso, ¡como la vida!

O: ¿Y cómo le hacen entonces? ¿De qué edad agarran al pollo?

F: ¿De qué edad?

O: Sí.

F: Diay, no, es que... Digamos, en este momento, digamos, desde que nacen, ahí llevan un proceso totalmente de un deportista. Desde que ellos nacen, la comida desde que ellos nacen es número uno, primera comida, porque usted no hace nada...

O: ¿Cuánto gasta, mae, al mes en la comida de un gallo?

F: A puede gastar usted... ¿En un solo gallo? En un solo gallo, usted puede unos 20 mil pesos ${ }^{15}$. Más o menos en vitaminas, y en todo, usted en un gallo puede gastar unos 20 mil pesos.

O: Es bastante para un animal tan pequeño, verdad...

F: Sí. Y por lo general, usted nunca tiene un gallo, un gallero nunca va a tener solo un gallo, nunca, siempre tiene mínimo diez, diez.

14 Gallo con plumas rojas y negras.

1520.000 colones. Aproximadamente 35 USD.

Cuadernos de Antropología 2014, 24(1), 37-64 
O: Ya. ¿Y cómo es el entrenamiento diario? O sea, ¿qué los ponen a hacer?

F: A mí por lo general... Es que es muy variable. Hay gente que le gusta tal cosa, que no le gusta lo otro, y usted le pregunta al gallero y le dice "no, no, es que eso no sirve", pero yo por lo general yo voy a lo que a mí me sirve, lo que a mí me sirve y siempre me ha servido, entonces a mí siempre me ha gustado el sol, O, siempre me ha gustado el sol, si yo tuviera tiempo, tuviera tiempo todos los días de poder dedicarme solo a eso, yo a mi gallo no le doy ejercicio, nada, yo los dejo todo el día, tal vez desde las 7 de la mañana o 6 y media de la mañana que es el mejor sol a 10, 11 de la mañana.

Todos los días, todos los días. Los descanso tal vez el domingo, domingo les pego unas pataditas con otro gallo ahí, un tope, para ver cómo él pelea, cómo va mejorando el cuido, si me falta algo, si no me falta, qué más tengo que hacerle, si está pasado de cuido, así...

O: ¿Cuándo sabe que un gallo está listo para pelear?

F: Por la cuita. Sí, la cuita, como él caga. Digamos, la cuita tiene un estado, si usted el gallo por lo general usted empieza a entrenarlo, empieza a darle comida, entonces el gallo empieza a botar todo, digamos, todo... Si usted lo agarra, usted, digamos, yo desde el principio, que yo agarro el pollo desde el principio, yo el pollo mío, yo no pretendo agarrar un gallo en un año, que lo solté en el patio y está comiendo pura tierra y puras lombrices y todo, y agarrarlo en un año y que sea el mejor gallo del mundo, nunca va usted poder hacer eso. Porque usted no... Diay, es lógico, usted no puede agarrar un animal, que lo va a ir a echar a peliar contra los mejores si usted no le dio la preparación antes, el desarrollo de un animal que usted sepa que va a ir a competir con, digamos, con la élite, usted no puede, ¡no puede, güevón!

Cuándo está para peliar... al principio usted empieza a quitarle la grasa, empieza a darle buen alimento, buena fibra, buena avena, proteínas, mae, entonces usted ya empieza a quitarle la grasa, entonces el gallo ya empieza a cagar más flojo, el gallo empieza a botar todo. Usted primero lo desparasita, primero que nada, llega y le da una pastilla para desparasitarlo y matarle todos los bichos, matarle todo el piojillo que trae de la pluma, ya empieza a cuidarlo. Entonces ya usted empieza a medir la plu... Eh, la cuita. La cuita tiene que ir avanzando, poniéndose más seca y más dura, por lo general se pone verde con una franja blanca. No sé por qué se pone así, vea, ellos no comen verde, o sea, no sé por qué se pone verde la cuita... 
Entonces el gallo no puede estar ni con mucha humedad, ni muy seco.

Entonces, digamos, yo agarro el gallo, cuitea ahí, donde yo lo tengo asoliando o donde esté limpio, la primera cuita que él bota, le doy tal vez un minuto, que la cuita se siente, entonces ya se seca y la agarro y la pego contra la pared. Si la cuita se queda pegada es que tiene mucha humedad, si se queda totalmente pegada, se queda ahí, se estripa, entonces tiene mucha humedad, entonces yo tengo que empezarle a meter más fibra al gallo para que se seque más. La cuita ideal es cuando usted agarra al gallo, levanta la cuita, la pega contra la pared y la cuita se queda tal vez unos segundos, unos 30 segundos y se cae, dura igual. Ahí es el momento en que usted dice "ya, ya mi gallo está listo", por dentro él.

O: ¿Les ponen nombre a los gallos?

F: Yo por lo general, a mí sí me gusta ponerle nombre al gallo...

O: ¿Por el pelo?

F: Sí, por el pelo, por el sentimiento que yo le doy y la vara, así. Más que todo, el nombre se basa por la forma de peliar del gallo...

O: ¿Pero qué nombres les dan?

F: Muchos así, o alguna historia, digamos, ahora mi amigo Fofo tiene un gallo que se llama "el pocas trancas". J, mi amigo, el gallo que vamos a llevar el domingo, se llama "el aguacero" porque ese gallo no deja al otro gallo ni peliar, es un aguacero peliando...

O: Pero no todos los galleros les ponen nombre a los gallos...

F: No, no todos, mucha gente no, nosotros es porque a mí me gusta y en realidad nosotros... Yo nunca preparo el gallo para peliar, yo lo quiero mucho y lo alisto para que él vaya a ganar y lo preparo para que él vaya con todas las ganas de ganar, yo nunca, nunca, o sea, nunca lo voy a echar a la muerte como dice la gente, yo lo alisto para que él siempre vaya a ganar, y que no se lastime y ojalá que gane rápido o que lo maten rápido, no me gusta que al gallo lo agarren y duren 10 minutos peliando, que lo tengan todo despichado, prefiero levantar el gallo mío, ya si el gallo mío está feo y no levanta las patas, prefiero meterme y juntarlo, aunque pierda la pelea, aunque pierda la plata, prefiero meterme y juntar mi gallo. 
La preparación del animal es medular. El gallo se entrena diariamente, lo cual supone, según este "Felo", un ethos que dignifica la actividad gallera como una actividad deportiva. Finalmente, la tendencia de ponerles nombre a los gallos implica cierta cercanía del hombre hacia el animal. Una familiaridad que está determinada por la calidad del animal al pelear.

\section{"Ese gallo estaba muerto, pero yo me lo llevé"}

Hay cierto código en las aprehensiones subjetivas de los galleros que tiene que ver con cierta idea de lo digno, del orgullo y del honor. Cuidar un gallo y que este gane paleas es sinónimo de reconocimiento, el "buen ojo" del gallero a la hora de escoger sus animales es muy importante según "Felo"; metafórica y simbólicamente, el dueño pelea cada una de las peleas de sus gallos.

O: ¿Pero sí duran mucho las peleas, ve’á?

F: Por lo menos ahora en general, antes eran 15 minutos, ahora están en 12 a 10 minutos, sí.

O: Y sí se dura bastante a veces... Son pocas, verdad, las peleas que duran poco...

F: Sí, hay pocas peleas, hay pocas peleas que empatan, también se van a empate, pero, por lo general, este... yo, a mí no me gusta que un gallo que empata o un gallo que dura mucho ya es un gallo que usted sabe que no, para qué usted lo va a preparar más si usted va a ver un gallo que, di, ya no hizo lo que tuvo que hacer, al menos... Es que tiene mucho que ver, es muy variable, porque a menos que el gallo suyo, digamos, en fuerte se lo adelanten, le den un tiro de muerte, pero el gallo suyo siguió para'o, tal vez por el cuido o la preparación que usted le dio, el gallo suyo tal vez se pudo defender un poco; entonces, el gallo suyo usted lo deja por lo menos para que él empate y lo salva, para, di, para no perder el cuido y no perder el gallo tal vez, tal vez en alguna pelea, en la próxima pelea, él sea mejor.

Yo le voy a contar una historia, yo tuve un... Nosotros tuvimos un gallo, cuando yo estuve allá en La XXXX [nombre de la gallera] con XXXX [un amigo recién fallecido], no era mío, era de un amigo, el mae lo compró y lo llevamos a peliar, la primera pelea, el gallo se puso como en un mes, mes y medio el gallo estaba listo pa’ peliar, él se puso muy rápido, entonces lo llevamos a peliar, muy bien.

¡Pum-pum! Se lo echamos a una gallina muy buena que a lo último nos dimos cuenta que tenía como siete peleas y el de nosotros era un pollito, diay, venía 
apenas era la primera pelea. El gallo de nosotros lo despedazaron de entrada, de entrada lo dejaron muerto, pero el gallo... a mí me gustó una cosa, que el gallo muerto, jél muerto! se quedaba amarrado del pico de la pluma, con el pico, al otro gallo y no lo soltaba y no lo soltaba, el otro gallo le tiraba patadas y el gallo no lo soltaba, el gallo no podía pararse porque estaba quebrado de la pechuga, él estaba quebrado de la pechuga entonces no podía pararse, pero él nunca soltó el pico, él siempre murió con el otro gallo así abrazado, pegado del pico.

A mí me gustó, todos mis amigos me decían "mae, ¿para qué lleva cochinadas a la choza, van a seguir con ese montón de cochinadas? Mátenlo, mátenlo, ¿pa' qué se va a llevar eso? Si usted sabe que eso no sirve, ya no sirve"... Al dueño del gallo yo le dije "mae, ¿lo va a matar?", me dice "sí, lo voy a matar, ya usted lo vio, no sirve", le digo "no, hágame el favor, si quiere me lo regala", me dice "no, está bien, yo se lo voy a dar", pero entonces todo mundo me criticó, me dicen "mae, ¿para qué se va a llevar ese gallo? ¿Para qué se lo va a llevar?”, a mí me gustó, me gustó, el gallo me gustó, "a él lo adelantaron" le digo, "a él lo adelantaron, le dieron un tiro de muerte, él no pudo hacer nada"... "No, no, no, no, eso no sirve, no sirve, ¿pa' qué se lo va a llevar?”, "no me importa”. Me lo llevé para la pila, lo lavé, lo alisté, lo guardé y me lo llevé en la maleta mía para mi casa. A los días, todo mundo me decía “mae, ¿pa' qué cuida a ese gallo? ¿Pa' qué cuida a ese gallo?", al gallo se le hizo unas pelotas en la pechuga de sangre majada, tuve que rajarlo, sacarle todo, volverlo a coser, bueno operarlo totalmente, sacarle todo...

\section{O: ¿Lo operó usted?}

F: Sí, yo lo operé. Como al mes, mes y medio, dos meses tal vez, el gallo se alistó, se volvió a poner, le digo yo "XXXX [amigo recién fallecido], me lo voy a llevar", “mae, ¿pa' qué va a llevar eso?” y yo... "Yo me lo voy a llevar”... Nos fuimos pa' la gallera, llevamos varios gallos, ganamos todos por dicha y ese día llevé el gallo mío, lo pesamos y lo llevé a la romana, cuando llegué a la romana me dice un señor “qué gallo más lindo, qué gallo más lindo, ¿con cuánto juega ese gallo?” "no", le digo yo, "voy a pesarlo y después hablamos, si tiene el mismo peso, hablamos", "ta bien"... Llego a la romana y lo peso, y dice "yo tengo un gallo pa' usté, ¿con cuánto juega?”, digo yo "no, no, juega barato, con media”, “ah no, no, no, con 75 lo mínimo", ya entonces le pregunto a todos mis amigos "mae, ¿le van a ir algo ${ }^{16}$ ?", "no, no, no, usted sabe que ese gallo va a perder, usted fue quien lo quiso

16 "Felo" le consultó a sus amigos si iban a apostarle algo de dinero a su gallo. Hay dos momentos de apuestas en las peleas de gallos. El primero, cuando entre los dueños de los gallos acuerdan un monto previo a la pelea, en este caso, el oponente de 
traer", ta bien... Como dicen, ya habíamos ganado con los otros gallos, entonces le aposté los 75 rojos yo solo. El gallo mío no duró ni 40 segundos y tenía el otro gallo despedazado, despedazado, despedazado, mae. Ya lo agarré y me lo llevé, ese día me gané el torneo, todo mundo quedó con la boca cerrada, hasta XXXX [el amigo fallecido] me decía “mae, Felo, mae, ¿cómo va usted a hacer eso?”, le digo yo "diay, padre, es que a mí me gustó el gallo, es que ustedes ven nada más si el gallo gana o pierde, usted no ve el momento como él perdió, ni nada, mae, usted nada más ve si perdió, di, se muere y si ganó, mejor, si ganó mejor, obviamente se salva. Pero usted, qué le pasó en la pelea, por qué él perdió, eso usted no lo ve, güevón, y no lo vieron"; después de ahí, ese gallo, vea, mae, ese gallo yo en un mes... Sí, es que hay que meterse en lo que el gallo hace, en un mes ese gallo yo me gané tres torneos, mae, ¡tres torneos me gané yo con ese gallo, mae! A todo mundo lo dejé con la boca... Viera el mae, el dueño del gallo, me decía "devuélvame ese gallo", "usted está loco, ¿no lo iba a matar?”, tres torneos, me gané el torneo en Naranjo, mae, 250 mil pesos me gané con ese gallo que había perdido la primera pelea, ¿tonces? En esta vara no se sabe nada. No se sabe nada.

O: Y cuando un gallo suyo gana, Felo, ¿qué siente usté?

F: ¡Ah es lo máximo, O! Es lo máximo, mae, eso es una adrenalina tan fuerte, mae, es inexplicable, mae, tendría que estar ahí para que lo vea... yo me imagino como un jugador, como cuando un jugador celebra un gol, exactamente, esas son las palabras. Sí. Y ojalá sea su gallo que usted lo sacó y lo crió desde hace un año, veá. Usted agarró un gallo, digamos, usted lo agarró y lo compró, usted lo ganó y usted dice "sí, muy bien, lo gané" pero el gallo no es mío... Se le dio cuido, yo lo cuidé y todo, en este momento es mío, porque yo lo compré, es mío, nadie me puede decir nada, pero en realidad no es mío, no es de mi sangre, yo no escogí ese gallo, ¿ya? Nada más fui y me gustó, me gustó como tutió, entonces sí, ¿cuánto vale? Tome, me lo llevo, pero el gallo no es mío. Entonces, eso le quita un poco de satisfacción a uno, lindo es cuando usted pelea un gallo y el gallo usted lo crió un año completo y el gallo suyo ganó, esa es la mejor sensación que usted puede

\footnotetext{
"Felo" quería jugar su gallo por no menos de 75.000 colones, "Felo" quería jugarlo con 50.000. Al faltarle 25.000, les pregunta a sus amigos si le van a ayudar con el resto de la apuesta. Esta dinámica de aportar dinero entre todos los amigos para llegar al monto de la apuesta es muy usual, al menos eso se pudo observar en las interacciones, así, si ganan, ganan todos, si pierden, pierden todos. El segundo momento de apuesta se da justamente durante la contienda, ahí, segundos antes del inicio de la pelea, los espectadores ven los gallos y valoran a cual apostarle, de esta forma convienen con otra persona de la tribuna: "Voy 10.000 al chile" otro asistente en otra zona del redondel dice, "bueno, yo le voy al cenízaro". La apuesta queda pactada de forma verbal. Al final, el asistente que apostó al gallo vencedor va por su dinero o bien, el perdedor se dirge al vencedor y cumple con el acuerdo previo. Pocas veces se observó que algún perdedor no quisiera pagar lo acordado, regularmente, la gente paga cuando pierde. Este segundo momento de apuestas puede extenderse durante toda la pelea, no solo al inicio de ésta.
} 
tener en la vida, la mejor, ganara un gallo suyo, que usted puede levantarse en medio redondel y que todo mundo diga "mae, qué gallo tiene usted, mae", usted lo levante y usted diga "este es mi gallo".

Geertz (1989) enuncia: "Buena parte del espíritu de Bali se manifiesta en un reñidero de gallos. Pues solo aparentemente son gallos los que combaten; en realidad son hombres (...) los gallos son considerados como penes separables, que obran por su cuenta órganos sexuales ambulantes con vida propia". Hasta acá, el gallo es una extensión del ego del gallero, desde él se dirimen un conjunto de afecciones ligadas al honor y al orgullo con un fuerte tono masculinizado. Un gallo, con Geertz, simboliza, en gran medida, el falo, aquella acepción de poder y autoridad de los hombres.

\section{"Él pelea hasta la muerte..."}

En este apartado, "Felo" se extiende sobre esta lógica del orgullo gallero. Se mostrará, en palabras del actor, cómo este código se proyecta en el gallo, el cual, según los galleros, decide pelear hasta el final, hasta su muerte; pareciera que la razón fundamental de esta tragedia es que el hombre no dirima sus asuntos hasta su muerte. De alguna forma, el gallo pelea para que el dueño no lo haga (en términos físicos); el duelo salva la barrera de una violencia más radicalizada.

O: Mae, pero, y... ¿Qué es la vara que los motiva, mae? Para criar un gallo y esperarse un año ${ }^{17}$ y después seguir... ¿Qué es la vara, mae?

F: Di, O, es como... Qué le puedo decir, mae, como un orgullo, como... No sé, es que es algo fuera de, no puede expresarlo usté, nada más es un orgullo... Es más, yo...

O: ¿Cuál es el objetivo de querer criar un gallo? ¿Cuál es el objetivo final? ¿Ir a peliarlo?

F: Ir a peliarlo y que el gallo gane. Porque usted como gallero eso... Di, yo soy gallero, mae, entonces yo para eso crío mis gallos, para que vayan al ring y mueran en la raya.

O: Y mueran en la raya.

17 Tiempo mínimo de cuido y preparación de un gallo fino. Antes de un año de edad, un gallo no se pelea, según lo afirmado por varios galleros. 
F: Sí, y mueran ahí en la raya peliando.

O: ¿Qué significa el gallo, mae, para usted?

F: Mae, el gallo es... Un animal que yo a veces me quedo hasta sorprendido porque usted no ve, mae, ningún otro animal que usted lo tenga tan herido, mae, y tan matado y él siga peliando, mae, hasta la muerte, porque él pelea hasta la muerte, mae, y sin ninguna razón, ni porque está en su casa ni nada, él usted lo lleva a otro lugar que él no conoce y pelea con otro animal que él nunca lo ha visto y él se muere peliando. Ahí él se va a morir ahí, de ahí no, ahí se muere, ahí se muere, eso es lo que tiene el gallo fino, mae. Y es una elegancia, ver un par de animales matarse, suena muy feo porque son a muerte, pero es una elegancia y un orgullo ver esos animales peliando, mae, que saber que es suyo es lo que le puedo decir, O, no, no sabía cómo responderle esa respuesta, mae.

O: Mae, en las galleras hay, yo he visto verdad, bueno, en esos redondeles, mae, hay gente de todas las edades, verdad, uno ve, mae, galleros viejos, mae, y uno dice "este hijueputa gallero sabe..."

\section{F: Claro...}

O: ¿Verdad? Pero de repente ve a estos chamacos, ¿verdad, mae? Y ve a unos maes que llevan los gallos así de ese color de los suyos; algunas peleas, eran como cuatro gallos, mae, y los hijueputas cuatro gallos ganaron; y le ganaron a gallos de, de...

F: Tal vez señores que tienen años.

O: Mae, oiga, pero años de que, diay que, tal vez desde chamacos, verdad, gente que uno dice "mae, este mae tiene 60 años" y tiene no sé cuántos años de jugar gallos... ¿Y qué es la vara, mae, verdad? ¿Por qué gana el chamaco y...? Porque usted estaba diciendo ahora "di mae, pero es la vara de la experiencia, veá, los viejos dicen, los viejos dicen" pero...

F: Hay que aprender de todo, O, pero el problema que tiene, ya ahora se ha corregido mucho, porque antes cuando yo empecé, el viejo nada más se ciñe en lo que él tiene. Un viejo a usted, digamos, yo soy un carajillo y yo le digo usted "yo 
tengo un gallo más bueno que usted", le digo a usted "se lo regalo", apuesto que el señor lo va y lo mata. Ni a putas agarra una gallina y se la echa al gallo. Por eso le digo el orgullo de un señor, de los señores viejos... Sí, tal vez en un tiempo él estuvo ganando y tuvo buenísimo, pero diay mae, la gente, la gente que le gusta esto, mae, igual que le gusta lo que sea, le gusta los caballos y que todo, tiene que buscar y saber quién tiene más bueno y no ser orgulloso, y decirle "mae, usted tiene un buen gallo, véndame uno"...

O: Y por qué, y por qué, mae, ¿por qué gallos? ¿Por qué no perros, por qué no gatos?

F: Por la razón que usted el gallo, usted lo cría, no lo puede criar... O sea, o sea, usted el gallo lo cría y es para peliar, la raza de él es para un gallo de pelea, por eso se llaman gallos de pelea. No es como un perro que usted un perro lo hace de pelea, usted la raza, hay razas de razas de perros, las mejores y las más bravas, la que tiene la presión en la mandíbula más fuerte y todo, pero usted ese perro por más bravo, de la raza más fuerte, digamos, que haiga pa' peliar y usted puede agarrar ese perro y lo cría desde chiquitico y es un perro manso, que no va a matar otro perro ni nada porque usted lo crió manso; con un gallo de pelea no se puede ser así. Por más que usted quiera criar un gallo de pelea que nunca pelee con otro gallo, no lo puede hacer, es imposible, prácticamente imposible, yo no he conocido a nadie que tenga un gallo de raza pura de pelea y sea manso, que no pelee con otro gallo, no existe, no existe. Por eso es que son gallos...

La violencia, condición sene qua non de este tipo de actividades, prefigura un elemento sugerente: para los galleros y su mundo de peleas de gallos, la violencia es necesaria, incluso, me atrevería a decir que, sin violencia, no existiría la "cultura de los galleros".

\section{"Usted juega el gallo y hasta que el gallo gane o pierda, usted paga..."}

Esta violencia toma varios matices y, en la mayoría de la ocasiones, se da una asociación entre estas dinámicas agresivas y masculinizadas con una lógica mercantil específica. El dinero resimbolizado como la apuesta es una de las dimensiones centrales de las peleas, uno podría pensar al gallo como una mercancía, lo cual en parte tiene sentido, porque, como el mismo "Felo" lo ha manifestado, el gallo tiende a cambiar su forma, no siempre es pensado como cosa mercantil. En ocasiones, el gallo es, como hemos visto, una extensión fálica del dueño; en otras, objeto de honor y orgullo y, claro, también, muchas veces, mercancia cambiable y desechable. 
O: Si no hubiera harina ${ }^{18}$, mae, de por medio, apuestas y toda esta vara, ¿habrían peleas de gallo? Si la gente no apostara.

F: Sí claro, yo considero que sí, sí. Jugar a puro orgullo porque yo llegaba al punto de decir... Sí, yo llegaba al punto que, digamos, ¡yo no tengo plata! ¡Nada! ¡Di, trabajo, guevón! Trabajo en construcción, qué voy a tener plata de nada. Yo llegaba al punto de... señores, que son señores finqueros, tal vez les guste los gallos por hobbie y tienen plata para jugar el gallo con un millón de pesos, y yo tal vez le digo "no, el gallo mío juega con 100 mil" y me dicen "ah no, papi, mejor venga cuando tenga plata", entonces yo llegaba al punto de decir "no, di juguemos el gallo de gratis a ver cuál gallo es mejor" porque yo sé que el gallo mío les va a ganar al de ellos... Entonces yo pienso que la plata no, para mí no tiene nada que ver, mae...

O: Para alguna gente sí, entonces.

F: Para mucha gente sí.

O: Si los maes no juegan el gallo por menos de la plata que ellos ponen es porque quieren ganar plata, ¿no?

F: Pero igual, la gente igual hay veces que han llegado a buscar y me dicen "no, está bien, el gallo mío juega con medio millón, pero echémoslo en 100" porque no, no... Cuando usted lleva un gallo a peliar, el gallo va a ir a peliar ya, porque el gallo está listo y no puede dejarlo más tiempo porque si no el gallo se pasa de cuido, entonces el gallo usted tiene que jugarlo, tiene que jugarlo, jugarlo, jugarlo...

Yo le maté un gallo a [un importante empresario nacional], entonces el mae es gallero, el [importante empresario nacional], en San Carlos, en una gallera yo le maté el mejor gallo que ese mae tenía, se lo maté con un gallo mío, guevón, vea lo que es la vida, mae, ese mae me lo cantó con un millón de pesos, mae, en la gallera, ¡está loco! yo agarré mi gallo y me di media vuelta, imagínese usted que le canten un gallo a usted con un millón de pesos cómo se le hace a usted el culito, ¿¡ah!? ¡Di, no, guevón! De casualidad solo esos dos pesos habían, el mío y el de él, solo esa pelea había.

Pasaron las peleas y pasaron todo, di, yo no pude jugar mi gallo y al rato llega el señor y se me arrima "bueno, está bien, yo le dije que el gallo mío jugaba con un

18 Dinero. 
millón, ¿pero con cuánto juega?” y no digo yo “di, yo se lo puedo echar con 150 lo más, más no puedo", "echémoslo con 200", digo yo "no, no, no, 150", "ta bien, echémoslo con 150"... Fue la mejor pelea de la noche, es más, ese día yo me gané, digamos, la apuesta y me gané 20 mil pesos más por la mejor pelea de la noche, mae, porque, mae, viera cuando yo jugué mi gallo, toda la gallera le iba al gallo del señor, dice el señor que tenía como 7 torneos, como 15 peleas ganadas, era un gallo de miedo, mae, miedo, mae, lo jugaba con un millón, guevón, si usted va a jugar un gallo con un millón usted tiene que saber... Primero tiene que tener plata y segundo tiene que saber lo que usted lleva, porque mentira que una persona que tenga planta, mentira que va a jugar un gallo con un millón solo porque tengo plata y es malo, sabiendo que usted lo puede perder. Y se lo despiché todo, mae, y el señor ya, después, el señor jugando de vivo al principio, y después cuando yo estaba en la pila ya lavando, porque el gallo mío quedó bien herido porque ¡no era un amor! ${ }^{19}$, ah, tampoco, era un animal... Mae, yo llegué a la pila, estaba lavando el gallo mío y el mae llegó y se me arrimó y me dice "chiquillo" ahí fue cuando me di cuenta que él era dueño de [una empresa muy importante], me dice "chiquillo, se acaba de ganar el mejor gallo de San Carlos” y yo "¿de verdad?" y me dice "sí, yo soy el dueño de [una empresa importante]" me dice, "y usted no sabe el gallo que usted se acaba de ganar, ni se imagina... Ni se imagina el gallo que se acaba de ganar", me dio la mano y me dice "buen gallo, ¿no lo vende?", me dice "le doy 200 mil pesos por ese gallo suyo" y me quedo yo así, hasta que me temblaban las manos, digo yo, di mae, yo acabo de ganar la pelea con $150 \mathrm{y}$ este mae me está dando dos tejas, mae... Pero nunca, nunca he, tras de que soy pobre nunca, nunca he vendido ni un solo gallo, mae, nunca, y me han ofrecido comprar esa búlica, la del torneo de Naranjo, la que le conté la vez pasada, que me gané tres torneos en un mes, un señor todavía me pregunta, yo llego, ese mae yo llego con unas búlicas y ese mae está y me dice "¿son hijas de aquel gallo?", Dios guarde yo le diga que sí porque ese mae le va toda la plata, toda la plata que tiene en la bolsa le va...

Sí, porque yo le gané toda la plata a él. Vea lo que es la vida, veá, hay gente que es muy orgullosa, pero los gallos... yo voy por hacer amistad, mae, y las mejores amistades que he tenido con galleros es porque les he matado el gallo o ellos me han matado el gallo a mí. Queda una vara que usted dice "puta, me mató el gallo", pero a la vez usted dice "puta, sí, mae..." es parte de una amistad, mae, es bonito, mae, a la vez usted no tiene que tener rencor ni nada, es un deporte, guevón, le llaman "el deporte de los caballeros", en Europa le llaman "el deporte

19 Era un gallo fuerte, valiente, peligroso.

Cuadernos de Antropología 2014, 24(1), 37-64 
de los caballeros" por la razón que usted diga "[el] gallo mío va con $100 \mathrm{mil}$, el suyo va con 100 mil” y usted juega el gallo y hasta que el gallo gane o pierda usted paga, usted no paga antes, hasta que el gallo suyo gane o pierda.

\section{"Yo los crío pa' peliar, yo no los crío pa' velos..."}

Retomando las ideas de la sección anterior, se puede decir, con Appadurai (1991), que las cosas poseen una trayectoria que no está dominada exclusivamente por la producción; es decir, el comportamiento de los objetos no debe de ser pensado únicamente bajo la ecuación producción-mercancía-producción o bien, mercancía-dinero-mercancía, para el autor arriba mencionado, la fase mercantil es solo una más dentro de la construcción de los objetos, las cosas tienen una vida social que no se limita a su momento productivo; en este sentido, hay que tomar en cuenta los intercambios, las distribuciones, además de los afectos y las emociones con que la gente aprehende cualquier tipo de cosa. Una vez interiorizada, una cosa puede dejar de ser simple mercancía para convertirse en algo con valor de uso (emocional incluso), pero desprovista de valor de cambio. Lo cual no quiere decir que esa cosa no pueda retornar a su fase mercantilizada.

Quizás así se puede explicar esta ambivalencia emocional de "Felo" hacia sus gallos, pues, en ciertos momentos, expresa por ellos una alta estima: los recoge de la arena casi muertos, los cura y vuelve a preparar, les habla con cariño y ternura, incluso, a uno de los gallos, como se verá en este apartado, le puso el nombre de un amigo recién fallecido (también gallero); es decir, en estas situaciones, el gallo trasciende su fase de simple cosa intercambiable ("yo no vendo gallos míos", suele decir "Felo" con cierto orgullo al hacer referencia a un legado personal); sin embargo, la misma narración del actor es tajante en afirmar que él cría gallos "para pelear", si no pelea, si el gallo no es buen gallo, se desecha. Lo cual hace retornar al gallo, casi de manera compulsiva, a su fase de mercancía utilizable o desechable ${ }^{20}$.

O: ¿Qué es lo más importante de la pelea?

F: ¿Lo más importante...?

O: ¿Qué es el elemento central de las peleas de gallo?

F: Para mí, para mí, lo más importante de una pelea de gallos es la preparación que usted lleve de su animal, como usted lleve su animal, ahí va toda la pelea, mae, ahí depende toda su pelea, como el animal suyo vaya preparado, para mí, veá. En

20 La excepción son los animales "padrotes", esto es gallos que han demostrado ser muy buenos gallos (han ganado muchas peleas), los cuales son conservados por sus dueños para perpetuar ese carácter bravío. 
son de peleas, en son de peleas para mí lo más importante es como su animal vaya preparado, eso es lo que más manda en todo.

O: ¿Y el gallo en sí?

F: También, tiene mucho que ver por la raza que usted lleva, veá, porque si usted lleva una mona ahí, obviamente va a saltar como mona, mae, di, es una mona, una mona es una mona, usted tiene que corregir, mae, yo desde chiquitico, mae, si yo veo que el pollo no me gusta, si el pollo se enfermó, si el pollo se le jodió una patilla, si se le jodió un dedo o le salió un dedo deforme, o el gallo tiene un ala caída, yo agarro y de una vez lo mato. A mí a veces mis amigos me dicen "mae, ¿cómo va a hacer eso?", le digo yo “mae, es que yo los crío pa' peliar, yo no los crío pa' velos", yo los crío pa' peliar y si un gallo viene deforme, tal vez los otros pollitos se desarrollaron grandísimos y quedó uno chiquitico y por más lindo que sea, hay que matarlo, porque él no va con buenas condiciones, ya él se está desarrollando mal, desde pequeños hay que criarlos a que sea la línea perfecta.

O: Una pregunta, una vez usted pelió un gallo, Felo, no me acuerdo en cuál gallera, mae, un gallo que, di mae, este, di corrió el hijueputa gallo, verdad, corrió, es decir, se acarracó. Este...

F: Sí, yo me acuerdo, claro.

O: Y usted me decía que usted estaba apenado, ¿por qué, guevón?

F: Porque esa es la peor vergüenza que usted puede tener como gallero, que un gallo no le pelee, mae, esa es la peor vergüenza. Usted puede perder un gallo, y lo puede perder, pero que el gallo suyo se muera ahí, en la raya, se muera en el redondel peliando hasta que lo maten, si el gallo suyo se salió de la pelea es porque no es un gallo fino, es un gallo que tal vez tenga una, digamos, un $75 \%$ fino y $25 \%$ no es fino, entonces tal vez donde venga donde lo haya comprado, o donde sea, no sea totalmente $100 \%$ gallo fino, entonces el gallo se fue, no le gustó el carey, no le gustó el carey y se fue. Esa es la peor vergüenza que un gallero puede sufrir en una pelea, que el gallo se le salga, que no quiera peliar más.

O: O sea, se quiere más a un gallo en el tanto este gallo sea un buen gallo. Los gallos malos no tanto, entonces... O sea, si un gallo sale bueno y ganó 10 peleas, ese hijueputa es el rey. 
F: Por lo general sí.

O: ¿Verdad? Un gallo así que no sirve, pues...

F: No sirve. Es más, de una hay que quitarlo. Claro. Claro, el gallo no sirve, el gallo entre más peleas así va siendo el más bueno, veá, y así el gallero lo estima más.

O: ¿Y la vara con la policía, Felo, qué?

F: Diay, no sé, esa vara es muy...

O: ¿Les ha llegado, les ha llegado a alguna gallera?

F: Claro, claro. En este... Hace poco sí estuvo muy fuerte, que mataban a los gallos y todo, gracias a Dios a mí nunca, ha llegado la policía, pero nos ha dicho "váyanse, nada más váyanse, ya aquí terminó todo, váyanse", nunca he tenido, por dicha, nunca he tenido la desgracia que me agarren el gallo y me lo maten, no sé qué haría, en ese momento no sé qué haría, al menos siendo un gallo que usted diga "mae...", tal vez no tenga, como dice usted, el gallo usted lo quiera más por las peleas que tenga, pero digamos yo, yo agarro un gallo que tengo ahí, se llama XXXX [nombre del amigo fallecido], se llama XXXX porque es en honor a mi amigo que se murió porque él fue que lo sacó, ese gallo a mí me lo quita la policía y tienen que llevarme con él, adonde se lo lleven tienen que llevarme con él, y así que no haiga ni peliado ni una sola vez, por el sentimiento que él tiene conmigo, veá, entonces yo no sé qué haría si llegara la policía, mae, no sé.

Antes de que pasaran estas broncas, mae, la ley llegaba a las galleras y decía "bueno, váyanse" o a veces llegaban, se daba una vuelta y la gente los sobornaba, usted sabe cómo está este país, todo es plata, la misma gente de la gallera los sobornaba y se quedaban un rato, les daban comida, se echaban un fresco y jalen, la palea seguía. Pero todo, todo, cayó tan feo por el diputado que agarraron, desde ahí fue cuando empezaron a matar gallos.

O: Sí, porque Senasa ${ }^{21}$ los agarra y los mata, ah.

F: Si Senasa los agarra, los mata. Igual como nosotros los matamos en el ruedo,

21 Servicio Nacional de Salud Animal. 
ellos los matan peor todavía ${ }^{22}$. Yo estuve leyendo un estudio que si el gallo no pelea se estresa mucho, por la forma en que usted los tiene, veá, que usted los... encerrados, no pueden estar juntos y estar encerrados en un espacio, si usted no llega a peliarlos por tanto tiempo, ellos se mueren de estrés y se calientan por la misma vara, la sangre les hierve tanto que ellos se mueren de estrés. El gallo fino, ah. Ellos no aguantan, ellos tienen que peliar, ellos la sangre tiene más de 2000 años, mae, antes de Cristo que pelean gallos, mae, esa sangre viene antes de eso, guevón. Entonces la gente ha venido evolucionando tanto esa genética que el gallo está hecho nada más pa' peliar, mae, nada más pa' peliar. Hay veces que yo le he llegado a echarle una gallina a un gallo para que él se entusiasme y ni siquiera la toma, mae, o sea ni siquiera la monta. Lo saco y le suelto un gallo y él es feliz peliando con el otro gallo...

El gallo suele ser imaginado como cosa mercantil, pero en algunos momentos de su trayectoria representa otras particularidades que lo hacen significar dimensiones alejadas de lo material, la vida social del gallo es versátil y dinámica, estos animales, para sus galleros, son polisignificativos. No se reducen a una sola acepción. Lo cual indica que no es posible monocaracterizar la lógica subyacente de las personas que juegan gallos.

\section{Conclusiones}

Este texto intentó aportar al conocimiento de la dinámica de la crianza y pelea de gallos, temática poco abordada por la academia y que presenta matices sugerentes que posibilitan pensar las diferentes formas en que las personas deciden apropiarse y dinamizar algunas tradiciones populares: ¿Cuáles son los sentidos que un gallero le imprime al cuido y entrenamiento de los gallos? ¿Qué significa el animal para el criador? ¿Qué tipo de actividades se suscitan en un redondel donde se juegan gallos? ¿Qué tiene que ver el honor, el orgullo, la hombría (dimensión masculinizada) y el prestigio, con la crianza y pelea de gallos? ¿Cómo podemos comprender la vida social de los gallos? ¿Son simples mercancías con valor de uso y de cambio o suponen otro tipo de trayectorias socioculturales? Y ¿Cómo podemos discutir la violencia desde las peleas de gallos? ¿Qué perspectivas nos aportan estos galleros desde sus realidades? ¿Cómo podemos ir más allá de la valoración negativa de la violencia?

Estas y otras preguntas fueron precisadas y profundizadas, no sin contradicciones claro está, desde las propia perspectiva del actor. La idea de la exposición de los hechos fue presentar a "Felo" desde contextos enunciativos que propiciaran la visualización de su particular forma de análisis de las diversas situaciones que acontencen en un proceso cotidiano de existencia, relacionado estrechamente con estos animales.

22 Al respecto, "Felo" mencionaba que cuando Senasa (Servicio Nacional de Salud Animal), llega a la peleas, decomisa a los animales. En una ocasión, según "Felo", los personeros de Senasa mataron a los gallos, el procedimiento utilizado fue introducir a los animales en un saco y, conectándolo a un escape de automóvil encendido, dieron fin a la vida de las aves.

Cuadernos de Antropología 2014, 24(1), 37-64 
El acuerdo tácito acá fue recordar que los sujetos, que nos ayudan en la construcción y deconstrucción de los diferentes objetos de estudios que nos se plantearon, tienen la capacidad de reflexionar sobre sus vidas y singularmente sobre aquellas cosas que llaman la atención como investigadores (as), más aún, como apunta Geertz (1989), son ellos quienes hacen interpretaciones de primer grado acerca de lo que les inquieta, el etnógrafo o la etnógrafa hará, en el mejor de los casos, precisiones de segundo o de tercer orden.

En este sentido, se buscó presentar la perspectiva del actor al intentar dotar al escrito de un matiz reflexivo que no solo presentara los hechos (el qué antropológico) y sus explicaciones concomitantes (el por qué antropológico), sino también, la forma en que los protagonistas caracterizan sus realidades (el cómo son los hechos para los actores) (Guber, 2008).

Así presentado, el diálogo permite posicionar a los sujetos en otros escenarios explicativos, los cuales muchas veces están ausentes de nuestras etnografías, porque es nuestra voz (la del antropológo o antropóloga) la que sobresale. Se intenta decir que la información recabada en campo puede tener múltiples interpretaciones, ninguna mejor que la otra, pero es necesario acordar espacios más amplios y pormenorizados a esta autoridad dialógica para que no siempre sea la voz imperativa del investigador la que predomine.

\section{Referencias bibliográficas}

Appadurai, A. (1991). La vida social de las cosas. México, D.F.: Grijalbo.

Bourdieu, P. (2010). La miseria del mundo. México, D.F.: Fondo de Cultura Económica.

Clifford, J. (2001). Dilemas de la cultura. Antropología, literatura y arte en la perspectiva posmoderna. Barcelona: Gedisa.

Fernández, F. (1984). Los juegos de gallos. Un veto histórico y un discurso parlamentario olvidado. San José: Asamblea Legislativa.

Freire, P. (2012). Pedagogía del oprimido. Buenos Aires: Siglo XXI.

Geertz, C. (1989). La interpretación de las culturas. Madrid: Gedisa.

Guber, R. (2008). El salvaje metropolitano. Buenos Aires: Paidós.

Levi-Satruss, C. (1988). Tristes trópicos. Barcelona: Paidós.

Malinowski, B. (1932). Argonauts of the western pacific. Londres: Georges Routledge and Sons, Ltd.

Mignolo, W. (2010). Desobediencia epistémica: retórica de la modernidad, lógica de la colonialidad y gramática de la descolonialidad. Argentina: Ediciones del signo.

Pritchard, E. (1992). Los núer. Barcelona: Anagrama.

Rodríguez, O. y Alpizar, N. (2014). Las peleas de gallos en la prensa escrita costarricense: un Análisis Crítico del Discurso en algunas noticias del diario La Nación S.A. Revista Rupturas, 4(1), 50-69.

Rosaldo, R. (1991). Cultura y verdad. Nueva propuesta de análisis social. México: Grijalbo.

Urbina, C. (2000). Homogeneizando culturas. Peleas de gallos, corridas de toros y estado en Costa Rica (1870-1914). Revista de Ciencias Sociales, 89, 59-67. 